\title{
Toxicity assessment and analgesic activity investigation of aqueous acetone extracts of Sida acuta Burn f. and Sida cordifolia L. (Malvaceae), medicinal plants of Burkina Faso
}

Kiessoun Konaté ${ }^{1,4^{*}}$, Imaël Henri Nestor Bassolé ${ }^{2}$, Adama Hilou' ${ }^{1}$ Raïssa RR Aworet-Samseny ${ }^{3}$, Alain Souza ${ }^{4}$, Nicolas Barro ${ }^{5}$, Mamoudou H Dicko², Jacques Y Datté ${ }^{6}$ and Bertrand M'Batchi ${ }^{4}$

\begin{abstract}
Background: Sida acuta Burn f. and Sida cordifolia L. (Malvaceae) are traditionally used in Burkina Faso to treat several ailments, mainly pains, including abdominal infections and associated diseases. Despite the extensive use of these plants in traditional health care, literature provides little information regarding their toxicity and the pharmacology. This work was therefore designed to investigate the toxicological effects of aqueous acetone extracts of Sida acuta Burn f. and Sida cordifolia L. Furthermore, their analgesic capacity was assessed, in order to assess the efficiency of the traditional use of these two medicinal plants from Burkina Faso.
\end{abstract}

Method: For acute toxicity test, mice were injected different doses of each extract by intraperitoneal route and the LD50 values were determined. For the subchronic toxicity evaluation, Wistar albinos rats were treated by gavage during 28 days at different doses of aqueous acetone extracts and then haematological and biochemical parameters were determined. The analgesic effect was evaluated in mice by the acetic-acid writhing test and by the formalin test.

Results: For the acute toxicity test, the LD50 values of $3.2 \mathrm{~g} / \mathrm{kg}$ and $3.4 \mathrm{~g} / \mathrm{kg}$ respectively for S. acuta Burn f. and S. cordifolia L. were obtained. Concerning the haematological and biochemical parameters, data varied widely (increase or decrease) according to dose of extracts and weight of rats and did not show clinical correlations. The extracts have produced significant analgesic effects by the acetic acid writhing test and by the hot plate method ( $p<0.05$ ) and a dose-dependent inhibition was observed.

Conclusion: The overall results of this study may justify the traditional uses of S. acuta and S. cordifolia.

\section{Background}

Indigenous medicinal plants were and are still one of the sources of modern medicines [1]. Moreover the trend of using phytotherapy as alternative medicine has increased the interest for the tropical plants' pharmacognosy [2].

In Africa, especially in Burkina Faso, medicinal plants still play an important role in health care of an important

\footnotetext{
* Correspondence: mehekiessoum@yahoo.fr

'Laboratory of Biochemistry and Applied Chemistry, University of Ouagadougou, 09 P.O.Box: 848, Ouagadougou 09, Burkina Faso ${ }^{4}$ Laboratory of Animal Physiology, Electrophysiology and Pharmacology, Faculty of Sciences, University of Science and Technology of Masuku, Franceville, Gabon

Full list of author information is available at the end of the article
}

portion of the population. This is because they are cheap, are locally available and efficient. Generally, the effects of medicinal plants are attributed to their content in active chemicals [3]. In developing countries there is a general belief among the consumers that the use of medicinal plants is always safe because they are "natural". However, evidences suggest otherwise and some studies suggest that some of the herbs can be associated with health hazards. Medicinal plants can contain many active chemical compounds and also other substances of great complexity like mucilages, polyphenols, polysaccharides, etc. [3]. That may modulate and modify the effects of any "active principles". Thus, some herbal remedies can be toxic or can act either as agonists or antagonists of the 
active principles. Therefore, the study of toxicity is an essential prerequisite for the efficiency assessment of plant extracts.

An ethnobotanical investigation in the central region of Burkina Faso has shown that many species are traditionally used to treat various kinds of pain diseases. Among such plants, S. acuta Burn f. and S. cordifolia L. (Malvaceae) are the most frequently and widely used. These plants are used to treat infectious diseases in children such as malaria, fever, pain, variola, and also have antibacterial, anti-inflammatory, analgesic and hepatoprotective properties $[3,4]$. In most cases, the drugs are administrated over a long period of time and without any proper monitoring of the dosage.

Previous data showed that aqueous acetone extracts of S. acuta Burn f. and S. cordifolia L. contain saponosides, coumarins, steroids, phenolic compounds and alkaloids. In addition, their extracts have showed good antioxidant and anti-inflammatory activities [5]. Despite their interesting biochemical features, the toxicology profile and the analgesic properties of these extracts are lacking. The aim of this contribution is to evaluate the toxicity of aqueous acetone extracts of S. acuta Burn f. and S. cordifolia L., as well as their analgesic properties.

\section{Methods}

\section{Identification of the plant materials}

S. acuta Burn f. and S. cordifolia L. were collected in August 2008 in Gampela, $25 \mathrm{Km}$ east of Ouagadougou, capital of Burkina Faso. The plants were identified in the Laboratory of Biology and Ecology, University of Ouagadougou, where a voucher specimen was deposited.

\section{Preparation of extracts}

Fifty grams of powdered plant materials (dried in laboratory condition) was extracted with $500 \mathrm{ml}$ of acetone $80 \%$ (400 $\mathrm{ml}$ acetone $+100 \mathrm{ml}$ water) for $24 \mathrm{~h}$ under mechanic agitation (SM 25 shaker, Edmund BÜHLER, Germany) at room temperature. After filtration, acetone was removed under reduced pressure in a rotary evaporator (BÜCHI, Rotavopor R-200, Switzeland) at approximately $40^{\circ} \mathrm{C}$ and freeze-dried (Telstar Cryodos 50 freeze-dryer). The extracts were weighed before packing in waterproof plastic flasks and stored at $4^{\circ} \mathrm{C}$ until use. The yields of the extractions were measured with precision balance (ADVENTURER). For yield of the extracts (mass of extract x 100/mass of powder), we obtained $13.42 \%$ for S. acuta and $9.45 \%$ for S. cordifolia.

\section{Animals handling}

Swiss NMRI mice (25-30 g) and adult albinos Wistar rats (160-165 g) of both sexes were used for this study. All animals were housed in cages under controlled conditions of 12 -h light/and $12 \mathrm{~h}$ without light and $25^{\circ} \mathrm{C}$.
They received pellets of food enriched with $20 \%$ protein and water ad libitum. They were deprived of food for $15 \mathrm{~h}$ (but with access to drinking water) and weighed before the experiments. Experiments on the animals were performed according to the protocols already approved by the Institute of Health Sciences Research/ University of Ouagadougou (Burkina Faso) and met the international standards for animal study [6].

\section{Toxicity studies \\ For acute toxicity}

Swiss mice (male and female) were randomly divided into 7 groups ( 1 control group and 6 treated groups) of 6 animals (3 males and 3 females). The control group received water containing $10 \%$ dimethylsulfoxide (DMSO) administered intraperitoneally. The aqueous acetone extracts of S. acuta Burn f. and S. cordifolia L., suspended in $10 \%$ DMSO were administered intraperitoneally at doses of $1 ; 2 ; 2.5 ; 3 ; 4 ; 5$ and $6 \mathrm{~g} / \mathrm{kg}$. The general behaviour of the mice was observed for $120 \mathrm{~min}$ after the treatment. The animals were observed for morbidity and mortality once a day for 14 days. The number of survivors after the 14 days period was noted. The toxicological effect was assessed on the basis of mortality for 14 days, which was expressed by the median lethal dose value (Lethal Dose 50 or LD50) estimated from the regression of log-probit mortality rate [7].

\section{For subchronic toxicity study}

Wistar rats were divided into 5 groups of 6 animals (3 males and 3 females) for each type of extract. The first groups served as control, and they received water containing DMSO 10\%. The second, the third and the fourth group of rats received daily and orally (gavage) for 28 days respectively 75, 100, and $200 \mathrm{mg} / \mathrm{kg}$ of each of two type of extract (suspended in 10\% of DMSO). Body weight was weekly taken, and the animals were daily observed to detect any signs of abnormalities throughout the study period. At the end of the 28 days period, the animals were deprived of food for $15 \mathrm{~h}$. Then blood samples were collected by cardiac puncture for biochemical and hematological tests, and selected organs were carefully removed and weighed.

\section{Collection of blood samples}

Blood samples were collected by cardiac puncture in three tubes for haematology, glucose and serum analysis. The blood samples with heparin and those without anticoagulant were centrifuged at $3000 \mathrm{rpm}$ for $5 \mathrm{~min}$ to obtain plasma and serum respectively. Plasma was used to determine glucose $[8,9]$ and the serum for other biochemical parameters such as aspartate aminotransferase (AST) [10], alanine aminotransferase (ALT) [11], alkaline phosphatase (ALP) [12,13], total bilirubin and direct 
bilirubin [14], triglycerides [15], total cholesterol [16]. All these biochemical parameters were measured with a laboratory automat (Selectra XL Vital Scientific, Elitech Group Company).

Hematological analyses were performed on the whole blood using an automatic counter (Mindray Auto hematology Analyser BC-5500) to evaluate the following parameters: total red blood cells (RBC), hemoglobin, hematocrit, platelet count, leukocytes (WBC), neutrophilis, basophilis, eosinophils, lymphocytes, monocytes, $\mathrm{MCV}$ (mean corpuscular volume), $\mathrm{MCH}$ (mean corpuscular hemoglobin ) and $\mathrm{MCHC}$ (mean corpuscular hemoglobin concentration).

\section{Test of analgesic properties}

\section{Test of writhing induced by acetic acid}

The analgesic properties of the extracts were analyzed using the writhing (induced by acetic acid) on a mice model [17]. Nociception was induced by an intraperitoneal injection of $0.6 \%$ acetic acid with a dosage of $10 \mathrm{ml} / \mathrm{kg}$ of body weight. For each extract five groups of six mice were formed. Each animal of group I received $10 \mathrm{ml} / \mathrm{kg}$ of body weight of the vehicle (10\% DMSO in water), and those from group II received $100 \mathrm{mg} / \mathrm{kg}$ of body weight of paracetamol. Each animal from group III, group IV and group V were orally treated with 200; 400 and $600 \mathrm{mg} / \mathrm{kg}$ of body weight doses of extracts (dissolved in 10\% DMSO) respectively, one hour before acetic acid injection. The number of writhings occurring between 5 and $20 \mathrm{~min}$ after acetic acid injection was recorded. The analgesic effect was expressed as the percentage reduction of writhes in treated mice compared to those in the control. The percentage inhibition was calculated using the formula below:

(\%) inhibition $=(\mathrm{A}-\mathrm{B} / \mathrm{A}) \times 100$, where $\mathrm{A}$ is mean for the control group and $B$ is mean for the treated group.

\section{The formalin-induced nociception}

The analgesic effect of S. acuta Burn f. and S. cordifolia L. was also evaluated using the method of paw licking, induced by formalin [18]. The animals were divided into five groups of six mice. Each animal of Group I received $10 \mathrm{ml} / \mathrm{kg}$ of body weight of the vehicle solution $(10 \%$ DMSO in water) while those from group II received $100 \mathrm{mg} / \mathrm{kg}$ of body weight of paracetamol. The animals from the groups III, IV and V received orally respectively 200; 400 and $600 \mathrm{mg} / \mathrm{kg}$ of body weight doses of extracts (suspended in 10\% DMSO). One hour after drug administration, $20 \mu \mathrm{l}$ of formalin ( $2.5 \%$ in normal saline) was injected into the plantar surface of the left hind paw of mice. The time spent in licking the injected paw was recorded and expressed as the total licking time in early phase ( 0 to $5 \mathrm{~min}$ after formalin injection) and late phase (15 to $30 \mathrm{~min}$ ). The percentage inhibition was calculated as above.

\section{Statistical analyses}

Data were expressed as Mean \pm Standard deviation $(\mathrm{SD})$ of six experiments $(\mathrm{n}=6)$. Results were analyzed by

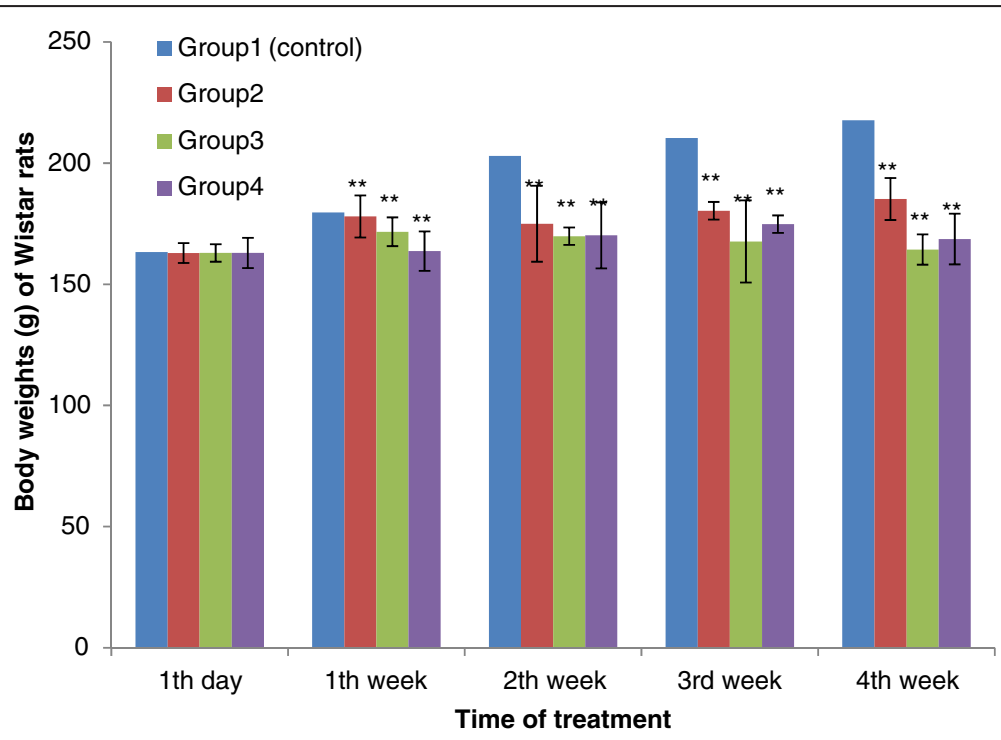

Figure 1 Effect of Aqueous Acetone Extract of Sida acuta on body weights (g) of Wistar rats with the time of treatment. Values are mean \pm S.E.M. ( $n=6$ in each group) one-way ANOVA followed by Dunnett's t- test: Compare all vs. control: $p>0.05,{ }^{*} p<0.05$, ** $p<0.01$ compared with control. Group 1: control, rats received 10\% DMSO. Group 2: rats received 10\% DMSO with extract (75 mg/kg body weight). Group 3: rats received 10\% DMSO with extract (100 mg/kg body weight). Group 4: rats received 10\% DMSO with extract (200 mg/kg body weight). 


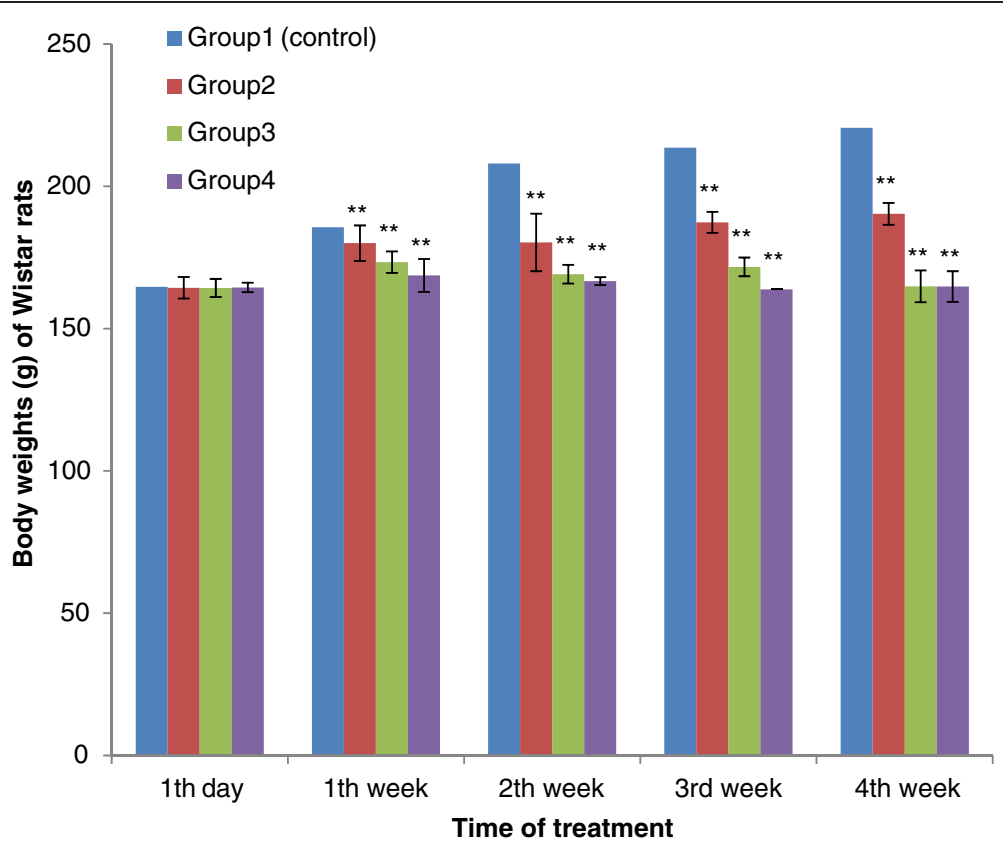

Figure 2 Effect of Aqueous Acetone Extract of Sida cordifolia on body weights (g) of Wistar rats with the time of treatment. Values are mean \pm S.E.M. ( $n=6$ in each group) one-way ANOVA followed by Dunnett's $t$ - test: Compare all vs. control: $p>0.05,{ }^{*} p<0.05,{ }^{* *} p<0.01$ compared with control. Group 1: control, rats received 10\% DMSO. Group 2: rats received 10\% DMSO with extract (75 mg/kg body weight). Group 3: rats received 10\% DMSO with extract (100 mg/kg body weight). Group 4: rats received 10\% DMSO with extract (200 mg/kg body weight).

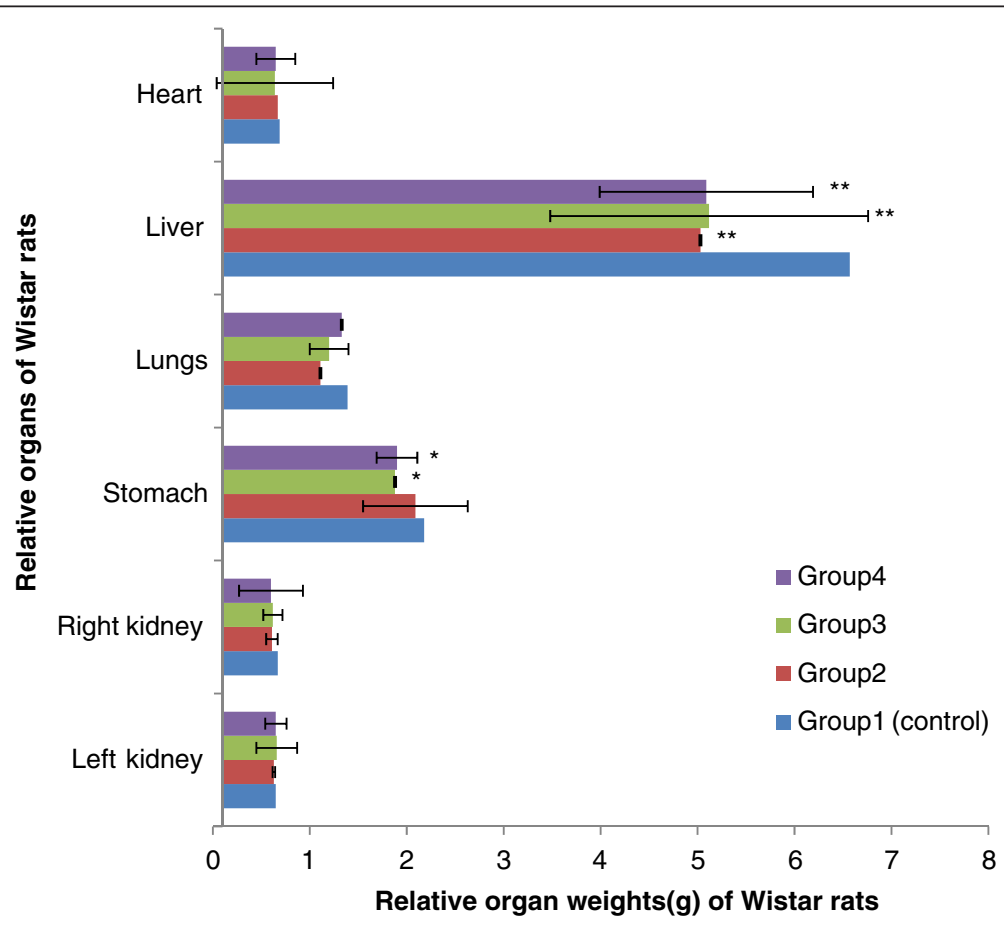

Figure 3 Effect of Aqueous Acetone Extract of Sida acuta on relative organ weights $\mathbf{( g )}$ of rats. Values are mean \pm S.E.M. ( $n=6$ in each group) one-way ANOVA followed by Dunnett's t- test: Compare all vs. control: $p>0.05$, ${ }^{*} p<0.05,{ }^{* *} p<0.01$ compared with control. Group 1: control, rats received 10\% DMSO. Group 2: rats received 10\% DMSO with extract (75 mg/kg body weight). Group 3: rats received 10\% DMSO with extract (100 mg/kg body weight). Group 4: rats received 10\% DMSO with extract (200 mg/kg body weight). 
one-way ANOVA followed by Dunnett's t-test using Prism 4 software. The level of significance was considered at $\mathrm{p} \leq 0.05$.

\section{Results}

Acute toxicity study of the plant extracts

For the acute toxicity study in mice, the following values of LD50 were obtained: $3.2 \mathrm{~g} / \mathrm{kg}$ and $3.4 \mathrm{~g} / \mathrm{kg}$ respectively for S. acuta Burn f. and S.cordifolia L.

\section{Concerning subchronic toxicity study in rats Body weights}

No significant difference in body-weight gain between control group and the test groups was observed in the first days of treatment $(\mathrm{p}>0.05)$. However, with four weeks, a significant decrease in body weight was noticed between the test groups and the control groups $(\mathrm{p}<0.01)$. The results are summarised in Figure 1 and Figure 2.

\section{Relative organ weights}

Figure 3 and Figure 4 show the effects of extracts on weight of some vital body organs of rats. No significant difference for kidneys, stomach, lungs and heart ( $p>0.05$ ); but we noticed a significant decrease about the liver weight between the treated groups and the control group (p <0.05).

\section{Haematological analysis}

The effects of extracts on the haematological parameters are summarised in Table 1 . There is a significant decrease for monocytes, basophils, haemoglobin, haematocrit and MCV between the control group (10\% DMSO) and the treated groups ( $\mathrm{p}<0.05$ or $\mathrm{p}<0.01)$.

\section{Biochemical analyses}

Table 2 shows the effects of extracts on the biochemical parameters. For certain biochemical parameters (AST, ALT, ALP) one observed a significant increase ( $p<0.01)$; however for the other biochemical parameters (glucose, creatinine, urea nitrogen, triglycerides, total bilirubin and direct bilirubin), there is a significant decrease between the control group (10\% DMSO) and the other treated groups $(\mathrm{p}<0.05$ or $\mathrm{p}<0.01)$.

\section{Analgesic properties}

\section{Acetic-acid writhing test}

The extracts have effectively reduced the number of abdominal muscle contractions induced by $0.6 \%$ acetic acid solution. The extracts produced significant inhibition of writhing induced by acetic acid. The inhibition was

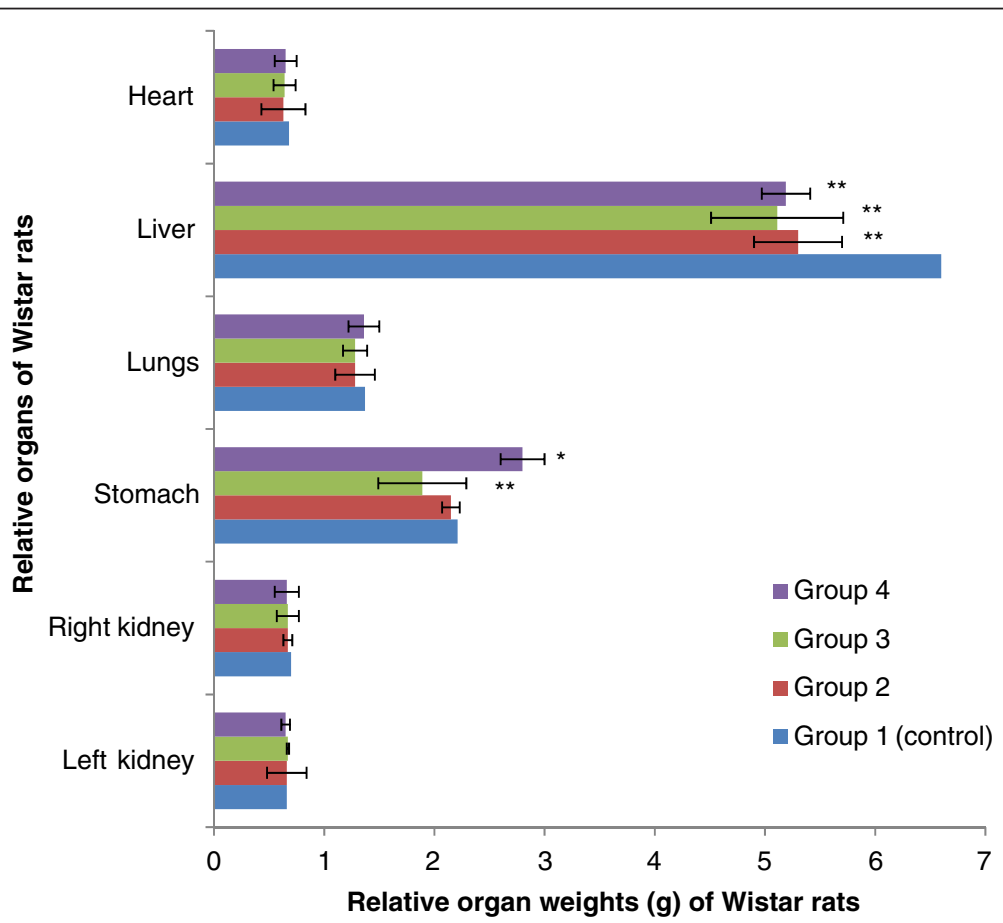

Figure 4 Effect of Aqueous Acetone Extract of Sida cordifolia on relative organ weights $\mathbf{( g )}$ of rats. Values are mean \pm S.E.M. ( $n=6$ in each group) one-way ANOVA followed by Dunnett's $t$ - test: Compare all vs. control: $p>0.05,{ }^{*} p<0.05,{ }^{* *} p<0.01$ compared with control. Group 1: control, rats received 10\% DMSO. Group 2: rats received 10\% DMSO with extract (75 mg/kg body weight). Group 3: rats received 10\% DMSO with extract (100 mg/kg body weight). Group 4: rats received 10\% DMSO with extract (200 mg/kg body weight). 
Table 1 Effect of Aqueous Acetone Extracts of Sida acuta and Sida cordifolia on the haematological parameters on whole blood of rats

\begin{tabular}{|c|c|c|c|c|}
\hline Haematological parameters & Group 1 & Group 2 & Group 3 & Group 4 \\
\hline \multicolumn{5}{|c|}{ Sida acuta Aqueous Acetone Extract } \\
\hline $\mathrm{WBC}\left(10^{3} / \mu \mathrm{l}\right)$ & $12.43 \pm 3.20$ & $12.19 \pm 0.10^{\mathrm{ns}}$ & $11.69 \pm 1.20^{\mathrm{ns}}$ & $11.77 \pm 0.11^{\mathrm{ns}}$ \\
\hline $\mathrm{RBC}\left(10^{6} / \mu \mathrm{l}\right)$ & $7.17 \pm 1.18$ & $7.23 \pm 2.36^{\mathrm{ns}}$ & $7.13 \pm 1.03^{\mathrm{ns}}$ & $7.08 \pm 0.88^{\mathrm{ns}}$ \\
\hline Eosinophil (\%) & $2.18 \pm 0.68$ & $2.21 \pm 1.08^{\mathrm{ns}}$ & $2.00 \pm 2.20^{\mathrm{ns}}$ & $2.11 \pm 4.53^{\mathrm{ns}}$ \\
\hline Lymphocyte (\%) & $78.11 \pm 0.24$ & $77.85 \pm 1.57^{\mathrm{ns}}$ & $77.69 \pm 1.43^{\mathrm{ns}}$ & $78.00 \pm 2.21^{\mathrm{ns}}$ \\
\hline Neutrophil (\%) & $25.89 \pm 0.09$ & $25.78 \pm 0.31^{\mathrm{ns}}$ & $25.59 \pm 1.43^{\mathrm{ns}}$ & $25.81 \pm 1.21^{\mathrm{ns}}$ \\
\hline Monocyte (\%) & $1.57 \pm 0.24$ & $1.02 \pm 1.20^{*}$ & $1.00 \pm 1.43^{*}$ & $0.91 \pm 1.21^{*}$ \\
\hline Basophil (\%) & $0.17 \pm 0.09$ & $0.13 \pm 0.31^{\text {ns }}$ & $0.11 \pm 0.43^{* *}$ & $0.12 \pm 0.22^{\text {ns }}$ \\
\hline Haemoglobin (g/dl) & $15.23 \pm 1.13$ & $14.69 \pm 0.15^{\mathrm{ns}}$ & $14.21 \pm 0.63^{*}$ & $14.11 \pm 0.77 *$ \\
\hline Haematocrit (\%) & $43.46 \pm 2.20$ & $44.00 \pm 1.21^{\mathrm{ns}}$ & $42.43 \pm 3.20^{*}$ & $40.61 \pm 1.2^{* *}$ \\
\hline $\operatorname{MCV}\left(\mu m^{3}\right)$ & $57.00 \pm 0.48$ & $56.48 \pm 1.28^{\mathrm{ns}}$ & $55.35 \pm 0.15^{*}$ & $54.79 \pm 2.30^{* *}$ \\
\hline $\mathrm{MCH}(\mathrm{pg})$ & $18.87 \pm 1.20$ & $18.62 \pm 0.43^{\text {ns }}$ & $18.90 \pm 1.22^{\text {ns }}$ & $18.49 \pm 0.67^{n s}$ \\
\hline $\mathrm{MCHC}(\mathrm{g} / \mathrm{dl})$ & $33.78 \pm 0.11$ & $33.35 \pm 2.22^{\mathrm{ns}}$ & $33.00 \pm 0.40^{\mathrm{ns}}$ & $33.13 \pm 1.22^{\mathrm{ns}}$ \\
\hline Platelet $\left(\times 10^{3} / \mu \mathrm{l}\right)$ & $967.42 \pm 4.12$ & $961.11 \pm 5.10^{\mathrm{ns}}$ & $953.22 \pm 2.35^{\mathrm{ns}}$ & $964.00 \pm 1.10^{\mathrm{ns}}$ \\
\hline \multicolumn{5}{|c|}{ Sida cordifolia Aqueous Acetone Extract } \\
\hline $\operatorname{WBC}\left(10^{3} / \mu \mathrm{l}\right)$ & $12.21 \pm 2.21$ & $12.08 \pm 0.54^{\mathrm{ns}}$ & $12.00 \pm 1.10^{\mathrm{ns}}$ & $12.02 \pm 1.22^{\mathrm{ns}}$ \\
\hline $\operatorname{RBC}\left(10^{6} / \mu \mathrm{l}\right)$ & $7.29 \pm 0.21$ & $7.45 \pm 0.15^{\mathrm{ns}}$ & $7.22 \pm 0.59^{\text {ns }}$ & $7.10 \pm 0.27^{\text {ns }}$ \\
\hline Eosinophil (\%) & $2.23 \pm 1.03$ & $2.14 \pm 0.56^{\mathrm{ns}}$ & $2.00 \pm 0.53^{\text {ns }}$ & $2.17 \pm 4.53^{\mathrm{ns}}$ \\
\hline Lymphocyte (\%) & 78. $31 \pm 1.03$ & $77.60 \pm 0.88^{\mathrm{ns}}$ & $77.62 \pm 1.20^{\mathrm{ns}}$ & $76.89 \pm 0.22^{*}$ \\
\hline Neutrophil (\%) & $26.13 \pm 0.68$ & $26.00 \pm 1.08^{\mathrm{ns}}$ & $25.78 \pm 2.15^{\mathrm{ns}}$ & $26.13 \pm 2.33^{\mathrm{ns}}$ \\
\hline Monocyte (\%) & $2.01 \pm 0.09$ & $0.76 \pm 0.31^{*}$ & $0.82 \pm 1.43^{*}$ & $0.91 \pm 1.21^{*}$ \\
\hline Basophil (\%) & $0.2 \pm 0.24$ & $0.17 \pm 0.10^{\text {ns }}$ & $0.17 \pm 1.25^{\mathrm{ns}}$ & $0.13 \pm 0.36^{*}$ \\
\hline Haemoglobin $(\mathrm{g} / \mathrm{dl})$ & $15.02 \pm 1.43$ & $14.40 \pm 0.31^{\mathrm{ns}}$ & $14.23 \pm 0.54^{\mathrm{ns}}$ & $14.75 \pm 1.21^{\mathrm{ns}}$ \\
\hline Haematocrit (\%) & $42.83 \pm 2.21$ & $42.60 \pm 1.10^{\mathrm{ns}}$ & $41.67 \pm 0.33^{*}$ & $42.00 \pm 0.22^{\mathrm{ns}}$ \\
\hline $\operatorname{MCV}\left(\mu \mathrm{m}^{3}\right)$ & $56.78 \pm 0.15$ & $56.62 \pm 0.34^{\mathrm{ns}}$ & $56.41 \pm 2.10^{\mathrm{ns}}$ & $56.80 \pm 0.33^{\text {ns }}$ \\
\hline $\mathrm{MCH}(\mathrm{pg})$ & $19.61 \pm 0.24$ & $19.57 \pm 0.22^{\mathrm{ns}}$ & $19.07 \pm 1.20^{\mathrm{ns}}$ & $19.55 \pm 0.36^{\mathrm{ns}}$ \\
\hline MCHC (g/dl) & $33.26 \pm 0.1$ & $33.51 \pm 0.54^{\mathrm{ns}}$ & $33.37 \pm 2.21^{\mathrm{ns}}$ & $33.00 \pm 0.2^{\mathrm{ns}}$ \\
\hline Platelet $\left(\times 10^{3} / \mu \mathrm{l}\right)$ & $960.11 \pm 0.33$ & $957.23 \pm 0.67^{\mathrm{ns}}$ & $963.47 \pm 1.63^{\mathrm{ns}}$ & $966.40 \pm 0.67^{\mathrm{ns}}$ \\
\hline
\end{tabular}

WBC: leucocyte count; $R B C$ : erythrocyte count; $M C V$ : mean corpuscular volume; $M C H$ : mean corpuscular haemoglobin; $M C H C$ : mean corpuscular haemoglobin concentration.

Values are mean \pm S.E.M. $(n=6)$ one-way ANOVA followed by Dunnett's $t$ - test: Compare all vs. control: $p>0.05,{ }^{*} p<0.05$, ${ }^{* *} p<0.01$ compared with control Group 1: control, rats received $10 \%$ DMSO.

Group 2: rats received $10 \%$ DMSO with extract $(75 \mathrm{mg} / \mathrm{kg}$ body weight).

Group 3: rats received $10 \%$ DMSO with extract (100 $\mathrm{mg} / \mathrm{kg}$ body weight).

Group 4: rats received 10\% DMSO with extract ( $200 \mathrm{mg} / \mathrm{kg}$ body weight).

dose-dependent. The results are presented in Figure 5 and Figure 6. However the extract of S. cordifolia has produced higher inhibition values comparatively to the extract of S. acuta.

\section{Formalin-induced nociception}

For the formalin-induced nociception; it can also be noticed that the extracts have significantly inhibited the inflammation induced by formalin. The extracts have inhibited the early phase ( 0 to $5 \mathrm{~min}$ ) and the second phase (15 to 30) of inflammation induced by formalin. The inhibition was also dose-dependent. The extract of
S. cordifolia has also produced higher inhibition than S. acuta (Figure 7 and Figure 8).

\section{Discussion}

About the acute toxicity, data indicated that the aqueous acetone extracts of $S$. acuta Burn $\mathrm{f}$. and S. cordifolia L. can be considered as weakly poisonous. Indeed, the literature reports that the substances with LD50 higher than $5 \mathrm{~g} / \mathrm{kg}$ b.w., by oral route are regarded as being safe or practically non-toxic [19]. This is an indication that the aqueous acetone extracts of S. acuta Burn f. and 
Table 2 Effect of Aqueous Acetone Extracts of Sida acuta and Sida cordifolia on the biochemical parameters in the plasma and the serum of rats

\begin{tabular}{|c|c|c|c|c|}
\hline Biochemical Parameters & Group 1 & Group 2 & Group 3 & Group 4 \\
\hline \multicolumn{5}{|c|}{ Sida acuta Aqueous Acetone Extract } \\
\hline Glucose (mmol/l) & $6.21 \pm 1.12$ & $4.28 \pm 0.022^{* *}$ & $3.17 \pm 0.11^{* *}$ & $3.39 \pm 0.01^{* *}$ \\
\hline Uric acid (mmol/l) & $0.17 \pm 1.18$ & $0.12 \pm 0.02^{\mathrm{ns}}$ & $0.12 \pm 0.01^{\mathrm{ns}}$ & $0.14 \pm 0.33^{\mathrm{ns}}$ \\
\hline Urea nitrogen (mmol/l) & $9.64 \pm 0.1$ & $9.41 \pm 0.22^{\mathrm{ns}}$ & $9.44 \pm 0.03^{\text {ns }}$ & $9.46 \pm 0.02^{\mathrm{ns}}$ \\
\hline Creatinine (mmol/l) & $0.053 \pm 0.01$ & $0.047 \pm 0.001^{\mathrm{ns}}$ & $0.048 \pm 0.003^{*}$ & $0.051 \pm 0.01^{*}$ \\
\hline AST (UI/I) & $79.5 \pm 2.20$ & $100 \pm 0.54^{* *}$ & $103.00 \pm 3.20^{* *}$ & $105.33 \pm 1.11^{* *}$ \\
\hline ALT (UI/I) & $39.5 \pm 5.40$ & $81.00 \pm 13.18^{* *}$ & $77.5 \pm 1.10^{* *}$ & $89.00 \pm 0.67^{* *}$ \\
\hline ALP (UI/I) & $71.5 \pm 2.00$ & $106.13 \pm 2.40^{* *}$ & $109.22 \pm 1.20^{* *}$ & $110 \pm 2.18^{* *}$ \\
\hline Triglycerides (mmol/l) & $0.80 \pm 0.06$ & $0.70 \pm 0.03^{\text {ns }}$ & $0.73 \pm 0.03^{*}$ & $0.74 \pm 0.01^{*}$ \\
\hline Total cholesterol (mmol/l) & $2.15 \pm 0.33$ & $2.03 \pm 0.01^{\mathrm{ns}}$ & $2.07 \pm 0.02^{\text {ns }}$ & $2.08 \pm 0.01^{\mathrm{ns}}$ \\
\hline Total bilirubin (mmol/l) & $0.14 \pm 0.01$ & $0.12 \pm 0.03^{\mathrm{ns}}$ & $0.12 \pm 0.01^{\text {ns }}$ & $0.13 \pm 0.02^{\text {ns }}$ \\
\hline Direct bilirubin (mmol/l) & $0.0013 \pm 0.11$ & $0.0012 \pm 1.10^{\mathrm{ns}}$ & $0.0011 \pm 0.01^{\mathrm{ns}}$ & $0.0013 \pm 0.01^{\mathrm{ns}}$ \\
\hline \multicolumn{5}{|c|}{ Sida cordifolia Aqueous Acetone Extract } \\
\hline Glucose (mmol/l) & $6.30 \pm 0.10$ & $4.41 \pm 033^{* *}$ & $3.51 \pm 0.11^{* *}$ & $3.60 \pm 0.67^{* *}$ \\
\hline Uric acid (mmol/l) & $0.173 \pm 1.10$ & $0.170 \pm 0.21^{\mathrm{ns}}$ & $0.169 \pm 0.33^{\mathrm{ns}}$ & $0.171 \pm 0.22^{\mathrm{ns}}$ \\
\hline Urea nitrogen (mmol/l) & $9.61 \pm 0.33$ & $9.49 \pm 2.20^{\text {ns }}$ & $9.55 \pm 0.67^{\text {ns }}$ & $9.58 \pm 1.21^{*}$ \\
\hline Creatinine (mmol/l) & $0.053 \pm 0.11$ & $0.034 \pm 1.22^{\mathrm{ns}}$ & $0.044 \pm 0.04^{\mathrm{ns}}$ & $0.047 \pm 0.01^{*}$ \\
\hline AST (UI/I) & $84.12 \pm 2.20$ & $97.67 \pm 3.10^{* *}$ & $100.60 \pm 1.21^{* *}$ & $102.33 \pm 0.33^{* *}$ \\
\hline $\mathrm{ALT}(\mathrm{UI} / \mathrm{I})$ & $41.62 \pm 11.61$ & $51.21 \pm 5.44^{* *}$ & $80.12 \pm 13.67^{* *}$ & $89.55 \pm 0.54^{* *}$ \\
\hline ALP (UI/I) & $73.51 \pm 1.74$ & $88.12 \pm 2.21^{* *}$ & $105.33 \pm 0.33^{* *}$ & $107.33 \pm 1.67^{* *}$ \\
\hline Triglycerides (mmol/l) & $0.58 \pm 1.15$ & $0.57 \pm 0.33^{\text {ns }}$ & $0.55 \pm 0.67^{*}$ & $0.57 \pm 0.54^{*}$ \\
\hline Total cholesterol (mmol/l) & $2.10 \pm 0.33$ & $1.62 \pm 0.15^{\mathrm{ns}}$ & $1.85 \pm 0.01^{\mathrm{ns}}$ & $2.01 \pm 0.67^{\text {ns }}$ \\
\hline Total bilirubin (mmol/l) & $0.2 \pm 0.071$ & $0.121 \pm 0.33^{*}$ & $0.130 \pm 0.033^{\mathrm{ns}}$ & $0.159 \pm 0.067^{* *}$ \\
\hline Direct bilirubin (mmol/l) & $0.0034 \pm 0.67$ & $0.0024 \pm 0.10^{\mathrm{ns}}$ & $0.0026 \pm 0.11^{\mathrm{ns}}$ & $0.0029 \pm 0.67^{*}$ \\
\hline
\end{tabular}

AST: aspartate aminotransferase; ALT: alanine aminotransferase; ALP: alkaline phosphatase.

Values are mean \pm S.E.M. $(n=6)$ one-way ANOVA followed by Dunnett's $t$ - test: Compare all vs. control:

$\mathrm{p}>0.05,{ }^{*} \mathrm{p}<0.05,{ }^{* *} \mathrm{p}<0.01$ compared with control.

Group 1: control, rats received $10 \%$ DMSO

Group 2: rats received 10\% DMSO with extract $(75 \mathrm{mg} / \mathrm{kg}$ body weight).

Group 3: rats received 10\% DMSO with extract (100 mg/kg body weight).

Group 4: rats received 10\% DMSO with extract ( $200 \mathrm{mg} / \mathrm{kg}$ body weight).

S. cordifolia L., have negligible level of toxicity when administered orally.

Concerning the subchronic toxicity study, no significant difference was observed in body weight gain between control group and the test groups during the first days of treatment. However, after the first week, we noticed a significant difference in body weight between the test groups and the control groups $(\mathrm{p}<0.01)$. The weak decrease in body weight observed in the rats treated with the highest doses (100 and $200 \mathrm{mg} / \mathrm{kg}$ b.w.) of the extracts, after the first week, may be due to low food intake and its non-optimal utilization. Severe growth depression as a consequence of reduced food intake in rats fed with a high-tannin content diet is well documented [20]. It's well known that tannins are found in high concentration in the extracts of $S$. acuta Burn f. and S. cordifolia L. [5].
The relative organ weight is also an important index of physiological and pathological status in man and animals. The heart, liver, spleen, kidney and lung are the primary organs affected by the metabolic reactions induced by toxicants [21]. Our results suggest that the aqueous acetone extracts are low toxic on these organs.

The analysis of blood parameters is relevant to risk evaluation because the haematological system has a higher predictive value of toxicity in humans when tests involve rodents [22]. The blood features are a good index of physiological and pathological status in man and animals and the parameters usually measured are haemoglobin, total red blood cells (RBC), leukocytes (WBC), MCV, MCH, MCHC, neutrophils, lymphocytes, eosinophils and number of platelets [23]. No significant difference was found in the majority of haematological parameters between the treated and the control groups. 


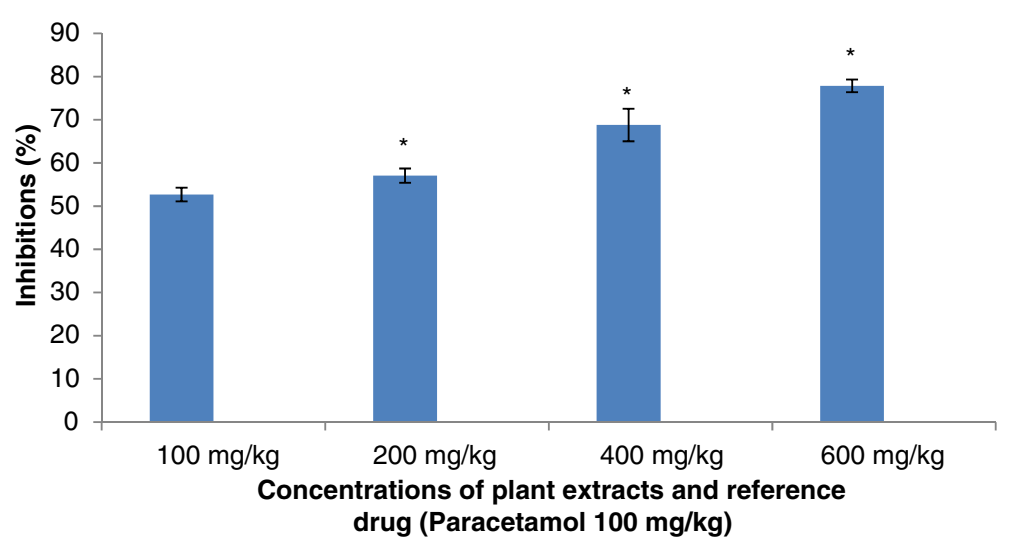

Figure 5 Effect of Aqueous Acetone Extract of Sida acuta on writhing-induced by acetic acid. Values are mean \pm S.E.M. $(n=6$ in each group) one-way ANOVA followed by Dunnett's t- test: Compare all vs. control: * $p<0.05$ compared with control.

This excludes the possibility of anaemia or disturbance linked to erythrocytes. However, a significant decrease was observed between the control group (10\% DMSO) and the treated groups for monocytes, basophils, haemoglobin, haematocrit and MCV ( $<<0.05$ or $\mathrm{p}<0.01$ ). This is an indication of the relative low toxicity of the aqueous acetone extracts on the haemopoetic system. The extracts of S. acuta Burn f. and S. cordifolia L. contain flavonoids [5] which have been shown to increase vascular integrity and also to act as antihaemorrhagic [24]. No obvious dose response was observed; however, changes observed between blood parameters do not suggest that the aqueous acetone extracts of $S$. acuta Burn f. and $S$. cordifolia L., produced toxicity in the treatment period. These differences may be explained by biological variation which is specific to each rat. [25].

The determination of creatinine, urea and uric acid are markers of kidney function [26]. In this present study, there is a significant (decrease) difference in creatinine and urea amount comparatively to the control group ( $\mathrm{p}<0.05)$. This was also confirmed by the low variation of kidney weights (right kidney and left kidney).

It was observed dose-dependent elevations of the serum enzymes in the serum enzymes in the treated groups. This indicates hepatocellular damages [27]. Previous studies $[28,29]$ reported that the increase in the activity of these enzymes in the plasma is often observed as a consequence of liver damage. The elevation in AST in all the treated groups and ALP in the highest doses groups suggest that other non-specific tissue damage also occurred because these enzymes have a wider distribution beyond liver [30-32]. However, it can be noticed that there is no too much difference in the levels of AST, ALT and ALP comparatively to the control group ( $\mathrm{p}<0.01$ or $\mathrm{p}<0.05$ ). The results revealed a relationship between these enzymatic markers and liver function and this was demonstrated by the decrease of liver weight.

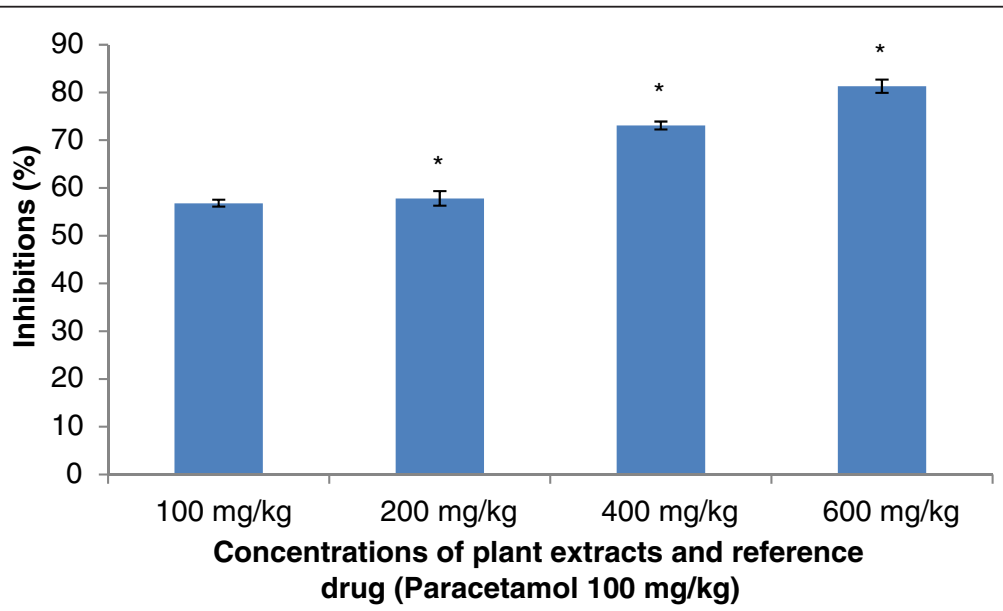

Figure 6 Effect of Aqueous Acetone Extract of Sida cordifolia on writhing-induced by acetic acid. Values are mean \pm S.E.M. ( $n=6$ in each group) one-way ANOVA followed by Dunnett's t- test: Compare all vs. control: * $p<0.05$ compared with control. 


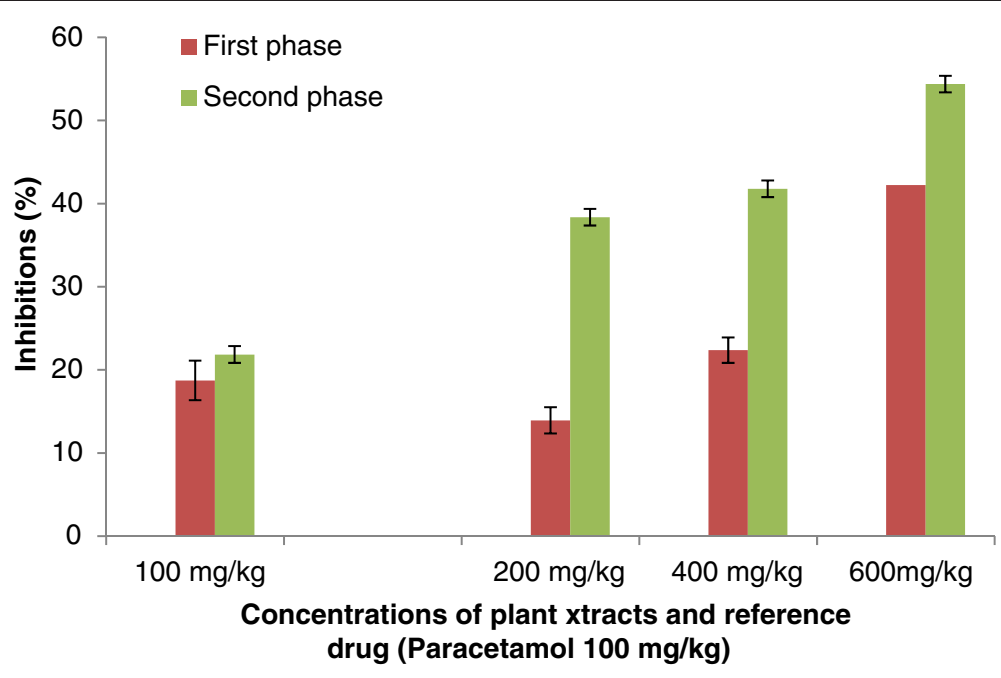

Figure 7 Effect of Aqueous Acetone Extract of Sida cordifolia on licking the hind paw-induced by formalin injection. Values are mean \pm S.E.M. ( $n=6$ in each group) one-way ANOVA followed by Dunnett's t- test: Compare all vs. control: $p<0.01$.

The treated groups have showed significantly lowered levels of bilirubin, urea and cholesterol. The decrease in bilirubin concentrations may be attributed to the depressant effect of the extracts. Some depressant compounds are known to decrease the concentration of bilirubin. The cholesterol concentration decreased in treated rats and this may indicate hepatocellular damage or malnutrition. It might also be that the extracts possess a hypo-cholesterolemic effect [33]. The serum urea concentration also showed a dose-dependent decrease following extracts administration. Urea is a product of protein metabolism that is excreted in urine and its retention in the body may indicate renal damage [34]. In addition, high levels of urea in control groups may be explained by the animals' food which contains proteins. Several studies have revealed that xanthine oxidase is responsible for the formation of uric acid from hypoxanthine or xanthine and is also responsible for the medical condition known as gout. In this sense, the decrease in urea, uric acid, and triglycerides during the treatment might be attributed to the fact that S. acuta and S. cordifolia have a xanthine oxidase inhibitory property [5].

Concerning the anti-nociceptive activity of extracts from S. acuta and S. cordifolia; abdominal injection of acetic acid was used to evaluate the extracts on their peripheral analgesic activity [35]. It has been reported

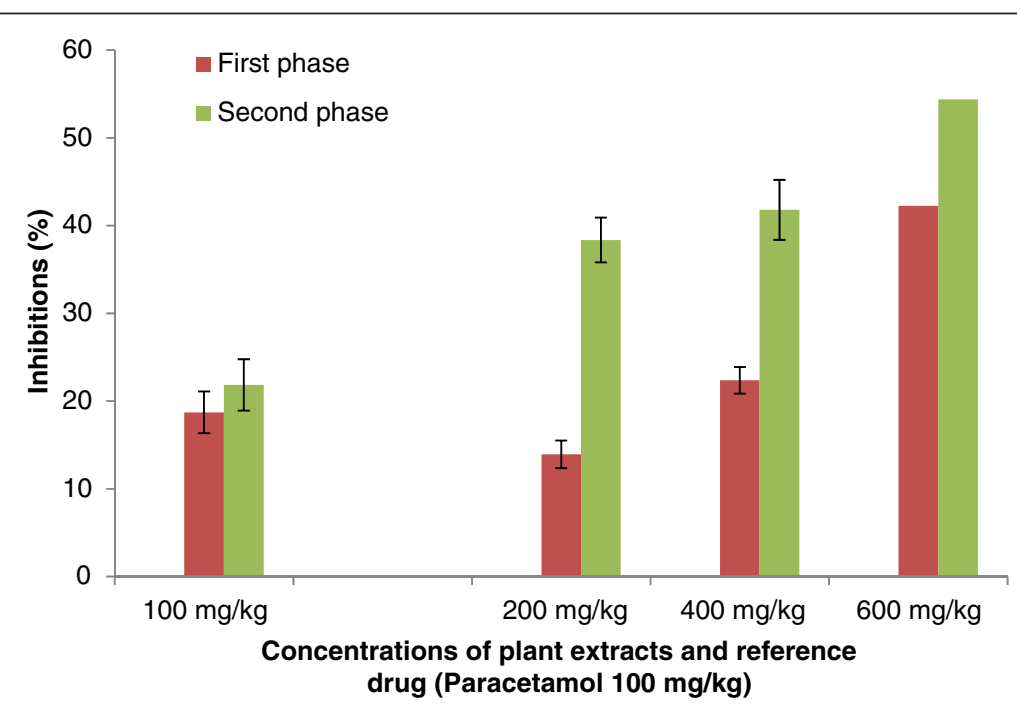

Figure 8 Effect of Aqueous Acetone Extract of Sida acuta on licking the hind paw-induced by formalin injection. Values are mean \pm S.E. M. ( $n=6$ in each group) one-way ANOVA followed by Dunnett's t- test: Compare all vs. control: $p<0.01$. 
that acetic acid irritates the peritoneal cavity leading to stimulation of local nociceptors located at the surface of the peritoneal cavity [36]. This leads to the release of prostaglandins and other algogens with subsequent stimulation of pain nerve endings [37]. Inhibition of the pain induced by acetic acid, by the extracts, suggests that they can probably work by suppressing the release of inflammatory mediators like prostaglandin, bradykinin and histamine [38]. According to the best of our knowledge, there is no data on the analgesic effect of the aqueous acetone extracts from S. acuta and S. cordifolia. Indeed, the oral administration of the aqueous acetone extracts from S. acuta and S. cordifolia produced significant inhibition of the acetic acid-induced abdominal writhing in dose-dependent manner. This inhibition was lesser than that produced by paracetamol. These results suggest that extracts from $S$. acuta and S. cordifolia can produce peripheral analgesic effect by inhibiting the chemical mediators and/or cytokines. The formalin test is a useful method to evaluate mild analgesic effect of drugs [39]. After formalin injection in hind left paw of mice two distinct phases are observed: the first phase (0 to $5 \mathrm{~min}$ ) or neurogenic phase comes from chemical stimulation that releases bradykinin and substance P. The second phase, coming 15-30 min after formalin injection, comes from the release of inflammatory mediators such as histamine and prostaglandin $[18,40]$. The aqueous acetone extracts of S. acuta and S. cordifolia have inhibited both phases, but the inhibition was more significant in the case of the late phase. Previous studies showed that analgesic activity can result from high flavonoids content as well as from free radical scavenging activity. Free radicals are involved in pain stimulation and antioxidants are known to inhibit such pains [41]. Moreover, recently discovered substances that have analgesic properties includes alkaloids, flavonoids and terpenoids compounds [42]. The presence of flavonoids in the extracts of S. acuta and S. cordifolia [5] can justify the analgesic activity of the extracts.

\section{Conclusion}

The very weak toxicity values are interesting features which can securize the use of Sida acuta and Sida cordifolia in the traditional medicine of Burkina Faso. The low toxicity, evidenced by LD50 values, suggests a wide margin of safety for therapeutic doses. The extracts have no significant negative effect on biological parameters. Moreover we obtained good analgesic results by testing the two species aqueous acetone extracts against animal model. Both findings justify the therapeutic use of these plants in folk medicine of Burkina Faso. There still remains the need for elucidating the molecular structures and the precise pharmacology of the active principles.
Competing interests

The authors declare that they have no competing interests.

\section{Authors' contributions}

KK and RRAS carried out the experiments and wrote the manuscript, IHNB, $\mathrm{AH}$ and $\mathrm{AS}$ supervised the work and the manuscript. NB, MHD, JYD and BMB contributed to the manuscript corrections. All authors read and approved the final manuscript.

\section{Acknowledgements}

The authors are grateful to the France Embassy in Burkina Faso and EGIDE-France for the mobility scholarship which helped for this research project. The authors thank Prof. Millogo/Rasolodimby from the Plants Biology Department of University of Ouagadougou for identifying the plant species.

\section{Author details}

${ }^{1}$ Laboratory of Biochemistry and Applied Chemistry, University of Ouagadougou, 09 P.O.Box: 848, Ouagadougou 09, Burkina Faso. ²Laboratory of Food Biochemistry, Enzymology, Biotechnology and Bioinformatic, University of Ouagadougou, 03 P.O.Box: 848, Ouagadougou 03, Burkina Faso. ${ }^{3}$ Institut Pharmacopoeia and Traditional Medicine, National Center for Scientific and Technological Research, P.O.Box: 1156, Libreville, Gabon. ${ }^{4}$ Laboratory of Animal Physiology, Electrophysiology and Pharmacology, Faculty of Sciences, University of Science and Technology of Masuku, Franceville, Gabon. ${ }^{5}$ Laboratory of Biochemistry and Molecular Genetics Microbial, University of Ouagadougou, 03 P.O.Box: 7131, Ouagadougou 03, Burkina Faso. 'Eaboratory of Nutrition and Pharmacology, Faculty of Biosciences, University of Cocody, Abidjan 22 P.O.Box: 582, Abidjan, Cote d'lvoire.

Received: 22 November 2011 Accepted: 5 August 2012

Published: 11 August 2012

\section{References}

1. Gupta SS: Propects and perpectives of normal plants products in medicine. Indian J Pharmacol 1994, 26:1-12.

2. Das S, Das S, Pal S, Mujib A, Dey S: Biotechnology of medical plants-Recent advances and potential. Hyderabad: UK 992 Publications; 1999.

3. Nacoulma OG: Medicinal plants and their traditional uses in Burkina Faso. PhD Thesis:: University of Ouagadougou, Biochemistry-microbiology department; 1996.

4. Karou D, Dicko MH, Simpore J, Traoré AS: Antioxiant and antibaterial ativities of polyphenols from ethnomedicinal plants of Burkina Faso. Afr J Biotechnol 2005, 2005(4):823-828.

5. Konaté K, Souza A: Polyphenol Contents, Antioxidant and AntiInflammatory Activities of Six Malvaceae Species Traditionally used to treat Hepatitis B in Burkina Faso. Eur J Sci Res 2010, 44:570-580.

6. Zimmermann M: Ethical guidelines for investigations of experimental pain in conscious animals. Pain 1983, 16:109-110.

7. Miller LC, Tainter ML: Estimation of the ED50 and its error by means of logarithmic probit graph paper. In: Proceedings of the society for Experimental Biology and Medicine 1944, 57:261-264.

8. Burn JM, Price CP: Measurement of blood glucose. Ann Clin Biochem 1985, 22:327.

9. Trinder P: Determination of glucose in blood using glucose oxidase with an alternative oxygen acceptor. Ann Clin Biochem 1985, 2:185-161.

10. Schumann G, Bonora R, Ceriotti F, Ferard G, Ferrero CA, Franck PFH, Gella FJ, Hoelzel W, Jorgensen PJ, Kanno T, Kessner A, Klauke R, Kristiansen N, Lessinger JM, Linsinger TPJ, Misaki H, Panteghini M, Pauwels J, Schiele F, Schimmel HG, Weidemann G, Siekmann L: IFCC primary reference procedures for the measurement of catalytic activity concentrations of enzymes at $37^{\circ} \mathrm{C}$. Part 5 . Reference procedure for the measurement of catalytic concentration of aspartate aminotransferase. Clin Chem Lab Med 2002, 40:725-733.

11. Schumann G, Bonora R, Ceriotti F, Ferard G, Ferrero CA, Franck PFH, Gella FJ, Hoelzel W, Jorgensen PJ, Kanno T, Kessner A, Klauke R, Kristiansen N, Lessinger JM, Linsinger TPJ, Misaki H, Panteghini M, Pauwels J, Schiele F, Schimmel HG, Weidemann G, Siekmann L: IFCC primary reference procedures for the measurement of catalytic activity concentrations of enzymes at $37^{\circ} \mathrm{C}$. Part 4 . Reference procedure for the measurement of 
catalytic concentration of alanine aminotransferase. Clin Chem Lab Med 2002, 40:718-724.

12. Committee on Enzymes of the Scandinavian Society for Clinical Chemistry and Clinical Physiology: Recommended methods for the determination of four enzymes in blood. Scand J Clin Lab Invest 1974, 33:291-306.

13. German Society for Clinical Chemistry: Recommendations of the German society for clinical chemistry. Standardisation of methods for the estimation of enzyme activities in biological fluids. Experimental basis for the optimized standard conditions. Z Klin Chem Klin Biochem 1972, 10:281-291

14. Sherwin JE, Thompson C: Liver function. Clinical Chemistry: Theory, Analysis, Correlation. EDS St Louis USA: Mosby Inc; 2003.

15. Fossati $P$, Prencipe $L$ : Serum triglycerides determined colorimetrically with an enzyme that produces hydrogen peroxide. Clin Chem 2077, 1982:28.

16. Allain CC, Poon LS, Chan CSG, Richmond W, Fu PC: Enzymatic determination of total serum cholesterol. Clin Chem 1974, 20:470-475.

17. Sawadogo WR, Boly R, Lompo M, Somé N, Lamien CE, Guissou IP, Nacoulmn OG: Anti-inflammatory, Analgesic and Antipyretic Activities of Dicliptera verticillata. Int J Pharmacol 2006, 2006(2):435-438.

18. Wilbool R, Sae WC, Reanmongkol W, Wongnawaa M: Antinociceptive activity of the methanolic extract of kaempferia galangal Linn. in experimental animals. J Ethnopharmacol 2008, 118:225-230.

19. Kennedy $G L$, Ferenz RLJ, Burgess BA: Estimation of acute toxicity in rats by determination of the approximate lethal dose rather than the $\mathrm{LD}_{50}$. J Applied Toxicol 1986, 6:145-148.

20. Fahey PR Jr, Jung HG: Phenolic Compound in Forage and Fibrous Feedstuffs. In Toxicants of plant origin IV Phenolics. Florida: CRC Press; 1989:123-190.

21. Dybing E, Doe J, Groten J, Kleiner J, O'Brien J: Hazard characterization of chemicals in Food and diet: doses response, mechanism and extrapolation issues. Food Chem Toxicol 2002, 42:237-282.

22. Olson H, Betton G, Robinson D, Thomas K, Monro A: Concordance of toxicity of pharmaceuticals in humans and in animals. Regul Toxicol Pharmacol 2000, 32:56-67.

23. Schalm OW, Jain NC, Carrol EJ: Veterinary Haematology. 3rd edition. Philadelphia: Lea and Febiger Publication; 1975:807.807.

24. Dharmancida S: Chinese Herbal Therapies for Immune Disorders. Inst. For Trad. Med. 2017SE Hawthorne. Portland: OR97214 Monograph; 1991:80.

25. Lewis RW, Billington R, Debryune E, Gamer A, Lang B, Carpanini F: Recognition of adverse and nonadverse effects in toxicity studies. Toxicol Pathol 2002, 30:66-74

26. Newman DJ, Price CP: Renal function and nitrogen metabolites. In Tietz textbook of Clinical Chemistry. Edited by Burtis CA, Ashwood ER. Philadelphia: W.B. Saunders Compagny; 1999:1204-1270.

27. Agaie BM: Onyeyili, Muhammad BY and Ladan MJ: Some Toxic Effects of Aqueous Leaf Extract of Anogeissus leiocarpus in Rats. Journal of Pharmacology and Toxicology 2007, 4:396-401.

28. Tilkian SM: Clinical Implications of Laboratory Test. Nissouri: The C.V. Moshy Company; 1979:11-17.

29. Woodman DD: Study of serum toxicity. J Applied Toxicol 1988, 84:249-254.

30. Boyd BW: Serum enzymes in the diagnosis of diseases in man and animals. J Comp Pathol 1988, 9:382-403.

31. Bush BM: Interpretation of Lboratory Results for Small Animal Clinicians. London: Backwell Scientific Publications; 1991.

32. Dial JM: Clinicopathological evaluation of the liver. Vet Clin 1995 25:275-293.

33. Odutola AA A, Co Zaria S: Rapid Interpretation of Routine Clinical Laboratory Test. Asekome, S and Company, Zaria, Nigeria 1992, 4:1-30.

34. Rabo JS: Toxicity Studies and Trypanosuppressive effects of stern bark extract of Butyrospermum paradoxum in Laboratory animals. University of Maiduguri: Ph D Thesis; 1998.

35. Chakraborty A, Deir RKB, Rita S, Sharatchandra K, Singh TI: Preliminary studies on anti-inflammatory and analgesic activities of Spilanthes acmella in experimental animal models. Ind J Pharmacol 2004 36:148-150

36. Bently GA, Newton SH, Stan J: Studies on the antinociceptive action of a agonist drugs and their interaction with opioid mechanisms. $\mathrm{Br} J$ Pharmacol 1983, 79:125-134.

37. Choi JH, Jung BH, Kang OH, Choi HJ, Park PS: The anti-inflammatory and anti-nociceptive effects of ethyl acetate fraction of Cynanchi paniculati Radix. Biol Pharm Bull 2006, 29:971-975.
38. Mehemet EB: Anti-inflammatory and antinociceptive properties of Dantrolene sodium in rats and mice. Pharmacol Res 2002, 15:127-130.

39. Hunskaar S, Fasmer OB, Hole K: Formalin test in mice, useful techniques for Evaluating mild analgesics. J Neurosc Meth 1985, 14:69-76.

40. Yi YL, Zong HA, Lu ZM, Xu HY, Zhang XM, Dou WF, Xu ZH: Analgesic and anti-inflammatory effects of the dry matter of culture broth of Termitomyces albuminosus and its extracts. J Ethnopharmacol 2008, 120:432-436.

41. Kim AK, Park SK, Zhou JL, Taglialatela G, Chung K, Coggeshall RE, Chung JM: Reactive Oxygen Species (ROS) play an important role in a rat model of neuropathic pain. Pain 2004, 111:116-124.

42. Musa YM, Haruna AK, M.llyas, AHYaro, Ahmadu AA, Usman H: Phytochemical, analgesic and anti-inflammatory effects of the acetate extract of the leaves of Pseudocedrella kotschyii. Afr J Trad Complement Altern Med 2008, 5:92-96.

doi:10.1186/1472-6882-12-120

Cite this article as: Konaté et al:: Toxicity assessment and analgesic activity investigation of aqueous acetone extracts of Sida acuta Burn $\mathrm{f}$. and Sida cordifolia L. (Malvaceae), medicinal plants of Burkina Faso. BMC Complementary and Alternative Medicine 2012 12:120.

\section{Submit your next manuscript to BioMed Central and take full advantage of:}

- Convenient online submission

- Thorough peer review

- No space constraints or color figure charges

- Immediate publication on acceptance

- Inclusion in PubMed, CAS, Scopus and Google Scholar

- Research which is freely available for redistribution

Submit your manuscript at www.biomedcentral.com/submit
C Biomed Central 